\title{
Preparation and Characterization of Organic-inorganic Hybrid Composite Film with Plate-shaped Alumina by Electrophoretic Deposition as a Function of Aging Time of Sol-Gel Binder
}

\author{
Doo Hwan Kim****, Hee Jeong Park*, Jinsub Choi**, and Hyung Mi Lim**; \\ *Eco-Composite Materials Team, Energy and Environment Division Korea Institute of Ceramic Engineering \\ and Technology, Jinju 52851, Korea \\ **Department of Chemistry and Chemical Engineering, Inha University, Incheon 22212, Korea \\ (Received April 14, 2015; Revised June 29, July 21, 2015; Accepted July 22, 2015)
}

\begin{abstract}
Sol-gel binder was prepared by hydrolysis and condensation reaction using boehmite sol and methyltrimethoxysilane as a function of aging-time. The coating slurry was composed of a plate-shape alumina in the sol-gel binder for the EPD process, in which particles dispersed in the slurry were deposited on the electrode under an electric field due to the surface charge. We studied the effects of three parameters: the content of boehmite, the aging time, and the applied voltage, on the physical, thermal, and electrical properties of the hybrid composite films by EPD. The amount of boehmite was $10 \sim 20 \mathrm{wt} \%$ and the aging time was $0.5 \sim$ 72 , with a fixed amount of plate-shape alumina of $10 \mathrm{wt} \%$. The condition of applied voltage was $5 \sim 30 \mathrm{~V}$ with a distance of $2 \mathrm{~cm}$ between the electrode during the EPD process. We confirmed that a structure of hybrid composite films of well-ordered plate alumina was deposited on the substrate when the film was prepared using a sol-gel binder composed of $15 \mathrm{wt} \%$ boehmite with $1 \mathrm{hr}$ aging time and EPD at $10 \mathrm{~V}$. The process shows a weight loss of $7 \%$ at $500^{\circ} \mathrm{C}$ in TGA and a breakdown voltage of $8 \mathrm{kV}$ at $87 \mu \mathrm{m}$.
\end{abstract}

Key words : Electrophoretic deposition(EPD), Boehmite, Sol-gel, Electric insulation, Aging time

\section{Introduction}

0 rganic and inorganic hybrid materials are important, since material properties of the components can provide synergy effects. The organic-inorganic hybrid coatings can improve mechanical, physical characteristics together with durability and used particularly for improvement of resistance against electric insulation, oxidation and corrosion. ${ }^{1-4)}$ Sol-gel method is a chemical synthesis method employed in inorganic polymerization reaction for preparation of inorganic materials as a raw material for glass and ceramics. In the past 10 years, organic-inorganic hybrid nano composites prepared by the sol-gel method have been used in the areas of ceramics, polymer chemistry, organic and inorganic chemistry, and physics. This method has lowtemperature processing characteristics providing unique opportunities to allow manufacturing of organic-inorganic hybrid materials. Low-temperature coating of sol-gel processes is important for the chemical industry requiring corrosion resistance and wear resistance as well as the electronic packaging requiring dielectric characteristics. ${ }^{1)}$

As a technique to produce coating films, there are methods using CVD and PVD processes. ${ }^{5-7)}$ The CVD includes

\footnotetext{
${ }^{\dagger}$ Corresponding author: Hyung Mi Lim

E-mail : lim@kicet.re.kr

Tel : +82-55-792-2450 Fax : +82-55-792-2469
}

atomic layer deposition (ALD) while the PVD includes sputtering, dip-coating deposition, spray-coating, electrophoretic deposition, etc. When coating is executed by using sputtering, a high vacuum atmosphere along with a high voltage are necessary, requiring much time and high cost to obtain coating films. Although dip-coating deposition and spray coating are available as a method to easily obtain the coating films without requiring the high vacuum atmosphere, they are accompanied by the inconvenience of increased coating frequencies and the problem of increased coating thicknesses. However, electrophoretic deposition method allows simpler setting than the gas phase method since desired thicknesses can be obtained as a function of coating times, and has an advantage of allowing prompt implementation of subsequent coatings since coating is conducted at room temperature.

Electrophoretic deposition (EPD) is a coating method using the principle of generating movement of electrical charges to anode or cathode by applying an electric field to particles having each of positive charges and negative charges in a colloidal phase. ${ }^{8)}$ This coating method allows coating on the surfaces of metal, polymer, ceramic, etc. Major variables of EPD may be divided into suspension and process variables. The suspension variables include size and shape of particles, composition of precursors, while applied voltage, deposition time, distance between substrates, type, surface condition, conductivity, etc. of substrate act as the process variables for EPD process. 
For hybrid composite materials applied as an electric insulation material, there are the results of filling spherical alumina particles of a few to a few ten micrometer in epoxy resin matrix and of producing silica of $5,20 \mu \mathrm{m}$ in size as a function of mixing ratios and filling contents. However, there is a problem of thermal stability with decomposition at $120^{\circ} \mathrm{C}$ even if inorganic materials such as alumina are added to the epoxy resin. ${ }^{9)}$ In the case of $\mathrm{MgO}^{-} \mathrm{ZrO}_{2}$ composites prepared through sol-gel process, it is difficult to produce a dense and defect-free thick film, while weight loss is measured to be $17 \%$ according to a thermogravimetric analysis up to $1000^{\circ} \mathrm{C}^{10)}$ When spray coating is conducted for once by using a sol-gel coating precursor, films of $10 \sim 25 \mu \mathrm{m}$ in thickness can be obtained, and repeated coatings are required to obtain a thick film for an improved dielectric breakdown strength $(17 \mathrm{kV} / \mathrm{mm}) .{ }^{11)}$ In the case of using a solgel coating agent and electrophoretic deposition method, thick films can be obtained as a function of coating times, and thick films of $400 \mu \mathrm{m}$ in thickness can be obtained in preparation of silica-alumina composite through EPD coating of slurry with dispersion of alumina in the case of using a silica sol-gel binder, while its breakdown voltage is on the level of $4.61 \mathrm{kV}{ }^{12)}$ When a boehmite sol-gel binder is applied by the same method, a dielectric breakdown strength of 55.5 $\mathrm{kV} / \mathrm{mm}$ is obtained in the case of boehmite-alumina composite. ${ }^{13)}$ The sol-gel binder is important because it can achieve low temperature sintering ceramic or organic-inorganic hybrid composite and its reactivity and densification may affect the physical properties of the result coating.

In producing EPD films which consist of sol-gel binder and plate-shaped alumina, effects of compositions and aging of the boehmite sol-gel binder on physical and electric properties of EPD films were studied.

\section{Experimental Procedure}

As starting materials to prepare electric insulation coating films of alumina organic-inorganic hybrid, boehmite (AlOOH, Catapal C200, Sasol), MTMS (Trimethoxymethylsilane, Dow corning), IPA (2-propanol, Dae Jung), acid catalyst (Acetic acid, Dae Jung), drying control chemical additives (DCCA), plate-shaped alumina $\left(\mathrm{Al}_{2} \mathrm{O}_{3}\right.$, RonaFlair white sapphire, Merck) were used. Fig. 1 shows TEM (transmittance electronic microscopy) and SEM (scanning

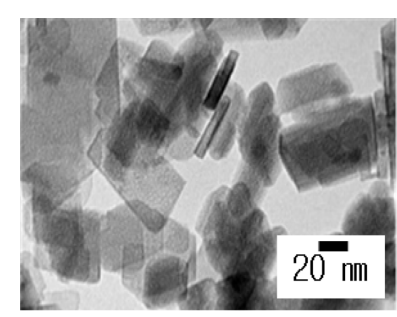

(a)

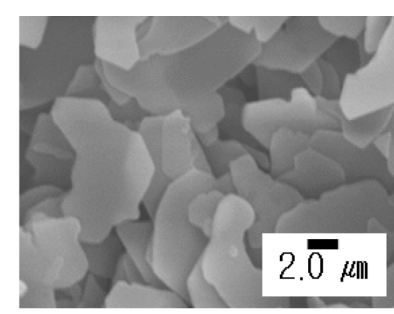

(b)
Fig. 1. (a) TEM image of $\mathrm{AlOOH}$ and (b) SEM image of $\mathrm{Al}_{2} \mathrm{O}_{3}$ particle. electronic microscopy) images of (a) boehmite and (b) alumina particles used in the present study.

Figure 2 shows sol-gel processes through (a) hydrolysis and (b) condensation reaction of MTMS as silane. Preparation processes for electric insulation coating agent are largely divided into two processes. The first is a process of producing a binder through sol-gel method from the mixed solution of boehmite dispersion phase and MTMS. After preparing the boehmite dispersion phase by dispersing 10 $20 \mathrm{wt} \%$ of bohemte in distilled water, MTMS, IPA, acid catalyst, DCCA were mixed as shown in Table 1 and agitated at $60^{\circ} \mathrm{C}$ and at a speed of $215 \mathrm{rpm}$ for preparation of the solgel binder as a function of variation in aging times. The aging times were set at $0.5,1,18,24,51,72$. DCCA was employed to prevent cracking upon drying of electric insulation coating films, for which DMF (N,N-Dimethylformamide, Dae Jung) was used. The second is a process of preparing an organic-inorganic hybrid coating agent for EPD by adding 10 wt $\%$ of alumina to the prepared sol-gel binder and agitating the mixture at room temperature for 30 minutes.

Electrophoretic deposition method is schematically illustrated in a simple way as shown in Fig. 3. Substrate used as the electrode was a nickel substrate of $40 \times 20 \times 0.2 \mathrm{~mm}$ subjected to degreasing by ethanol. Upon electrophoresis, the applied voltages were $5 \sim 30 \mathrm{~V}$, and experiments were conducted with deposition time and distance between substrates being fixed at 10 minutes and $2 \mathrm{~cm}$, respectively. EPD coating substrates were then dried at $100^{\circ} \mathrm{C}$ for 10 minutes, followed by heat treatment at $250^{\circ} \mathrm{C}$ for $60 \mathrm{~min}-$ utes. The rate of temperature rise upon heat treatment was $5^{\circ} \mathrm{C} / \mathrm{min}$, and the cooling rate was set at $2^{\circ} \mathrm{C} / \mathrm{min}$. Fig. 4 schematically illustrates the preparation process of $\mathrm{Al}_{2} \mathrm{O}_{3}$. $\mathrm{AlOOH}$ organic-inorganic hybrid electric insulation coating films utilizing EPD method.

Zeta potential was measured as shown in Fig. 5, after

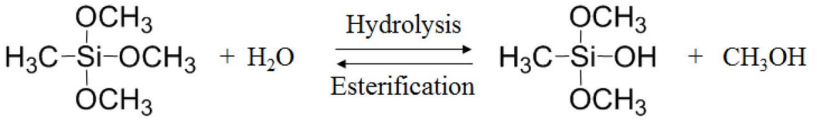

$$
\begin{aligned}
& \text { Monomer } \\
& \text { (a) }
\end{aligned}
$$

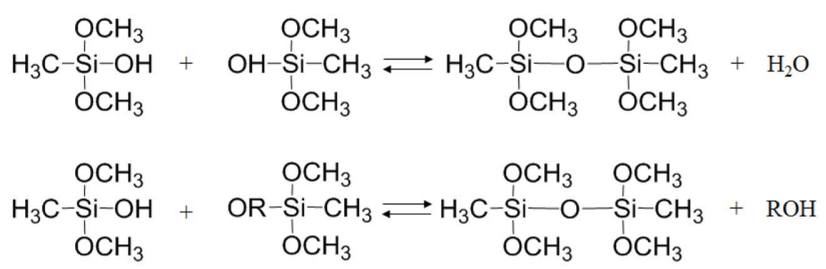

Fig. 2. (a) Hydrolysis of MTMS and (b) condensation (b) by sol-gel process.

Table 1. Composition of Sol-gel Binder with Boehmite Sol and Silane (wt\%)

\begin{tabular}{ccccc}
\hline $\begin{array}{c}\text { AlOOH sol } \\
(10 \sim 20 \mathrm{wt} \%)\end{array}$ & MTMS & Acid & IPA & DCCA \\
\hline 41.3 & 47.0 & 1 & 9.5 & 1.2 \\
\hline
\end{tabular}




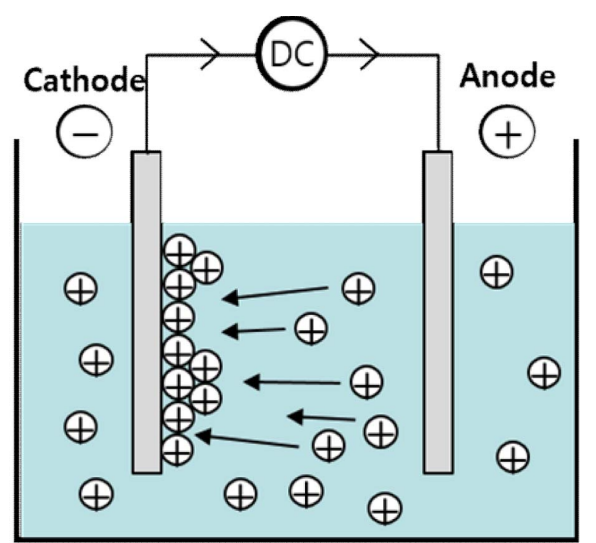

Fig. 3. Schematic illustration of electrophoretic deposition process.

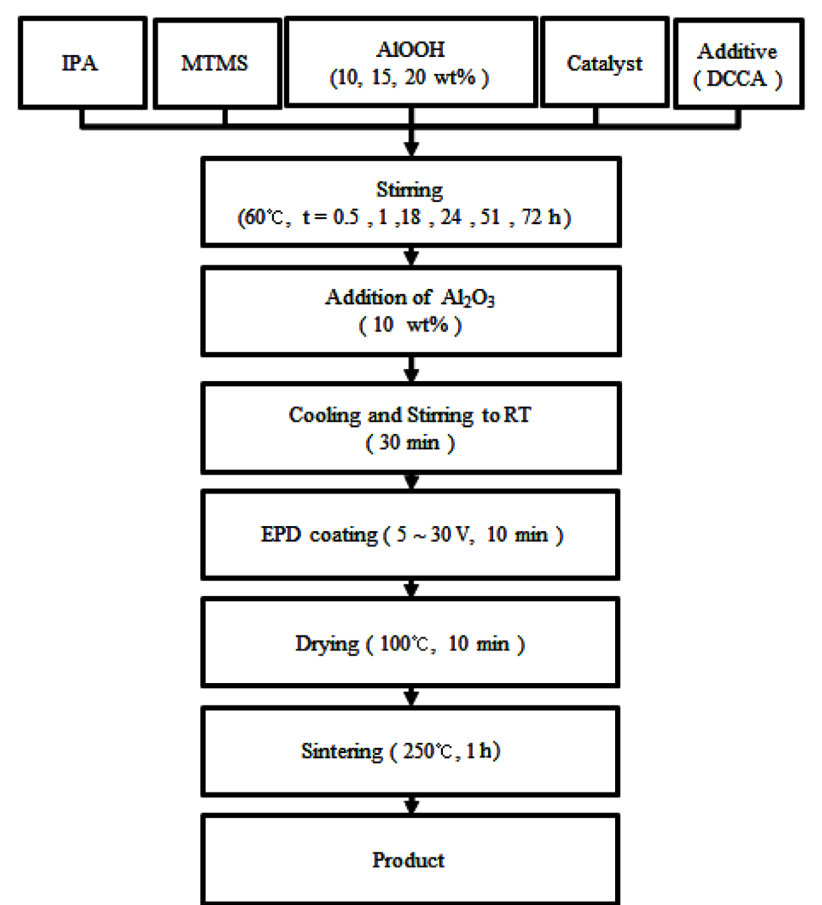

Fig. 4 Fabrication process of $\mathrm{Al}_{2} \mathrm{O}_{3}-\mathrm{AlOOH}$ organic-inorganic composite coating films.

dispersing $0.01 \mathrm{wt} \%$ of alumina and boehmite, respectively, in distilled water. Micron-sized alumina was ballmilled for $24 \mathrm{~h}$. Each suspension was measured in the range of $\mathrm{pH} 2 \sim \mathrm{pH} 10$.

Shapes and particle sizes of particles were measured by using TEM (JEM2000EX, JEOL, Japan), SEM (SM-300, Topcon, Japan) and an apparatus for measuring particle size distributions (LA-950, Horiba, Japan), while zeta potential was measured with an eletrophoretic light scattering spectrophotometer (ELS-Z, Otsuka Electronics, Japan). Thicknesses and microstructures of electric insulation coating films prepared by application of EPD were observed by a film thickness gauge (MiniTest 600, Elektrophysik, USA) and SEM, while a withstanding voltage meter (TOS5101, KIKUSUI, Japan) was used to check for electrical charac-

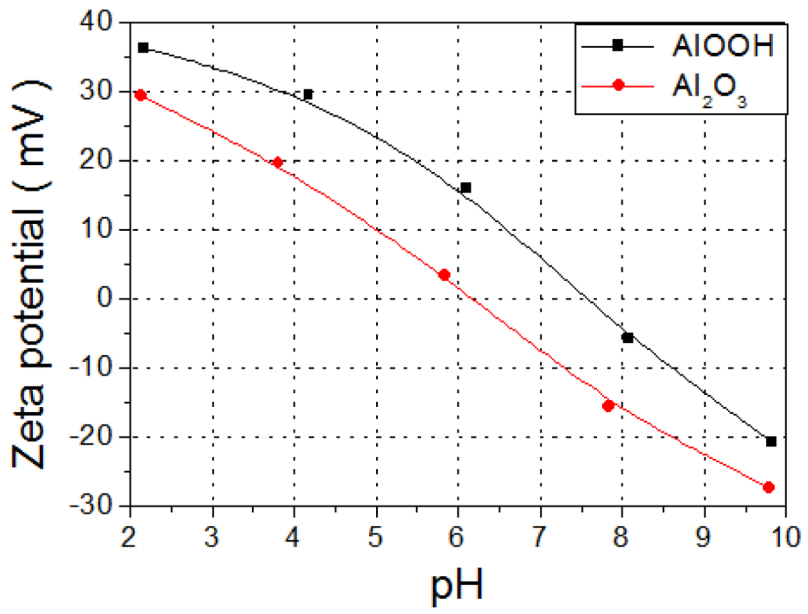

Fig. 5. Zeta potential of $0.01 \mathrm{wt} \% \mathrm{AlOOH}$ and $\mathrm{Al}_{2} \mathrm{O}_{3}$ particle milling for $24 \mathrm{hr}$ in dispersion of d.i water in terms of $\mathrm{pH}$.

teristics. Also, to evaluate thermal characteristics of the electric insulation coating films, TGA(DTG-60H, SHIMADZU, Japan) was conducted. Thermal analysis was performed in the temperature range of $25 \sim 900^{\circ} \mathrm{C}$ in air atmosphere under the condition for temperature rise rate of $10^{\circ} \mathrm{C} / \mathrm{min}$.

\section{Results and Discussion}

\subsection{Preparation of alumina-boehmite organic-inor- ganic hybrid coating films}

Zeta potential is a major factor for dispersion stability and mobility, and one of the major variables for EPD. Fig. 5 is a zeta potential graph for $0.01 \mathrm{wt} \%$ of boehmite and alumina dispersed in distilled water as a function of $\mathrm{pH}$ changes. Alumina having a large particle size in the order of micron was prepared as a suspension by ball milling for $24 \mathrm{~h}$. Upon checking for $\mathrm{pH}$ of the final coating agent, it was affirmed to be in an acid condition at $\mathrm{pH} 3.6$, at which zeta potentials of boehmite and alumina have positive charges. Boehmite and plate-shaped alumina with the surface charges having positive charges are coated onto cathode upon electrophoresis.

\subsection{Formation of coating films due to a change in applied voltages}

EPD process variables include applied voltage, deposition time, distance between substrates, type of substrate, conductivity, etc. Fig. 6(a) shows a change in thicknesses of electric insulation coating films as a function of an increase in applied voltages, indicating that thicknesses of electric insulation films were increased as the applied voltages were increased. Fig. 6(b) shows a change in breakdown voltages and dielectric breakdown strengths as a function of increase in applied voltages, where the highest breakdown voltage and dielectric breakdown strength were observed when the applied voltage was $10 \mathrm{~V}$. Upon electrophoretic deposition, 


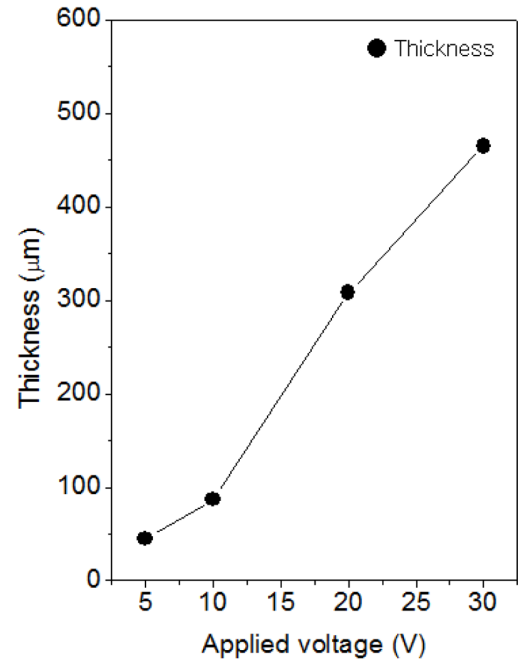

(a)

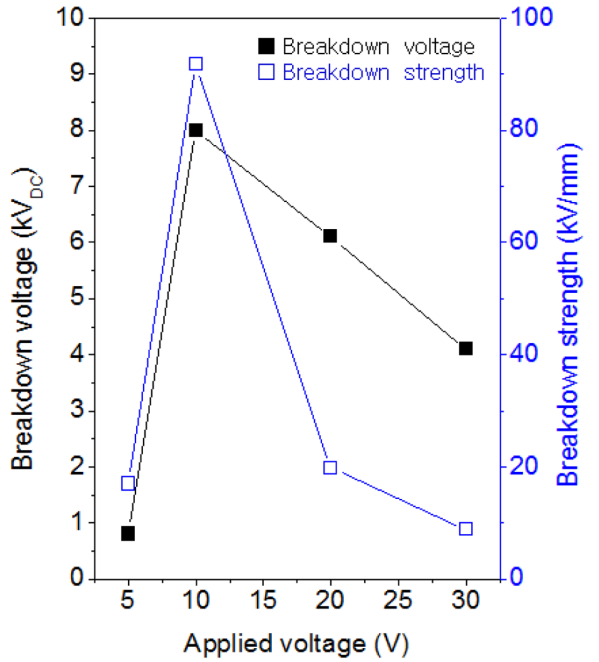

(b)

Fig. 6. (a) Thickness, (b) breakdown voltage and breakdown strength of coating films as a function of applied voltages for aging time of $1 \mathrm{~h}$.

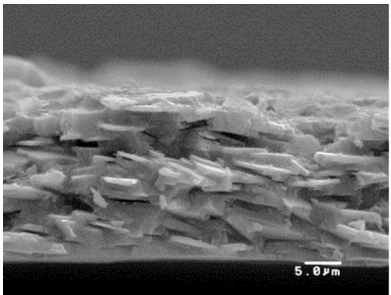

(a)

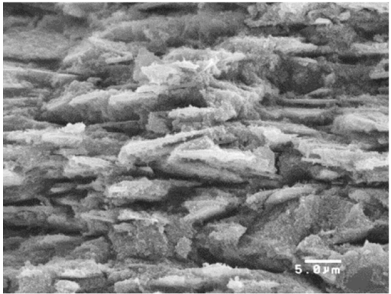

(c)

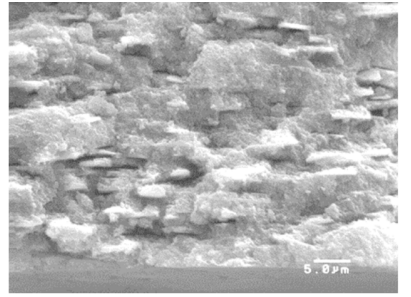

(b)

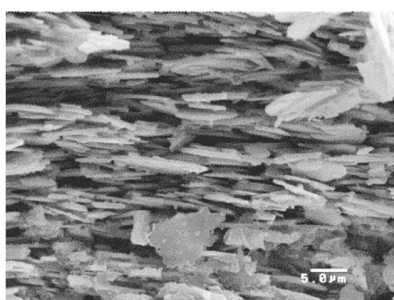

(d)
Fig. 7. Cross-sectional SEM images of coating films on nickel substrate 15 wt\% boehmite coatings by EPD as a function of applied voltage of (a) $5 \mathrm{~V}$, (b) $10 \mathrm{~V}$, (c) $20 \mathrm{~V}$, (d) $30 \mathrm{~V}$.

the applied voltage is considered to have an effect on structures and filling factors upon formation of the electric insulation films by affecting the sol-gel binder and mobilities of the plate-shaped alumina particles. The physical and electrical properties of the electric insulation films as a function of applied voltages are shown in Table 2.

Figure 7 and 8 show images and shapes of fracture surface, surface of the electric insulation coating films where the applied voltages were $5,10,20,30 \mathrm{~V}$, respectively. Although the sol-gel binder and the plate-shaped alumina were coated well on the substrate in the case of Fig. 7(a), the plate-shaped alumina particles can be seen to have been coated more than the sol-gel binder as shown in Fig. 7(d)

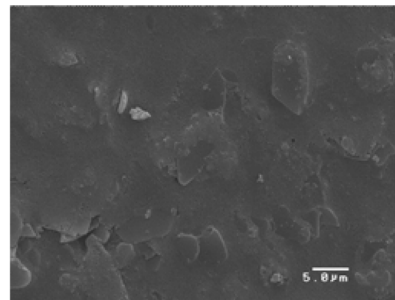

(a)

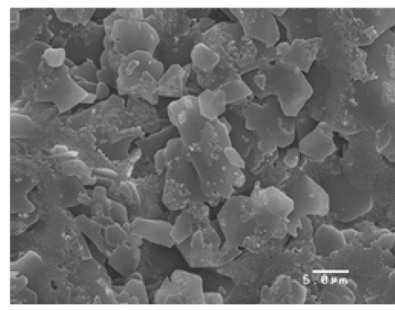

(c)

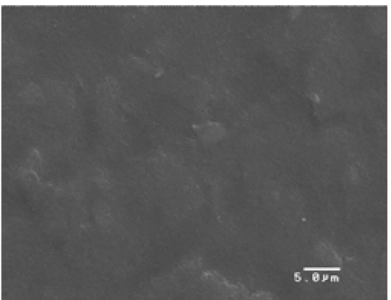

(b)

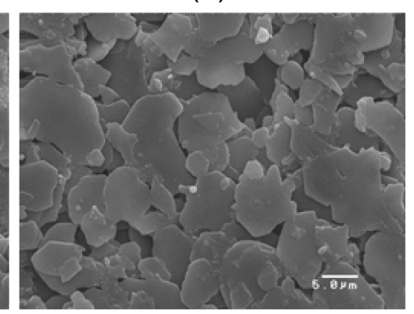

(d)
Fig. 8. SEM images of surfaces of coating films on nickel substrate in $15 \mathrm{wt} \% \mathrm{AlOOH}$ coatings by EPD as a function of applied voltage of (a) $5 \mathrm{~V}$, (b) $10 \mathrm{~V}$, (c) $20 \mathrm{~V}$, (d) $30 \mathrm{~V}$.

when the applied voltage is high at 30 V. Fig. 8 shows surface images of the electric insulation coating films as a function of change in applied voltages, where it is observed that the sol-gel binder partly failed to fill air gaps between particles at $20 \mathrm{~V}$ and $30 \mathrm{~V}$ although the sol-gel binder filled air gaps at $5,10 \mathrm{~V}$. When the applied voltage was $10 \mathrm{~V}$, a dense film was formed as the sol-gel binder filled the air gaps between plate-shaped alumina particles so that a high breakdown voltage of about $8 \mathrm{kV}$ (> $80 \mathrm{kV} / \mathrm{mm}$ ) is considered to have been measured even for the thicknesses below $100 \mu \mathrm{m}$. When the applied voltages were increased to higher than $10 \mathrm{~V}$, mobility of plate-shaped alumina were increased so that the sol-gel binder failed to fill the air gaps between 
Table 2. Physical and Electrical Properties of the Coating Films in terms of Applied Voltage

\begin{tabular}{|c|c|c|c|c|c|c|}
\hline No & $\begin{array}{l}\text { Voltage } \\
\text { (V) }\end{array}$ & $\begin{array}{c}\text { Weight } \\
\text { of Coating (mg) }\end{array}$ & $\begin{array}{c}\text { Apparent } \\
\text { density* }\left(\mathrm{g} / \mathrm{cm}^{3}\right)\end{array}$ & $\begin{array}{l}\text { Thickness } \\
(\mu \mathrm{m})\end{array}$ & $\begin{array}{c}\text { Breakdown } \\
\text { voltage }\left(\mathrm{kV}_{\mathrm{DC}}\right)\end{array}$ & $\begin{array}{c}\text { Breakdown } \\
\text { strength }(\mathrm{kV} / \mathrm{mm})\end{array}$ \\
\hline 1 & 5 & 30.6 & 1.5 & 45.2 & 0.8 & 17.0 \\
\hline 2 & 10 & 95.6 & 2.8 & 86.8 & 8.0 & 91.8 \\
\hline 3 & 20 & 359.5 & 2.4 & 308 & 6.1 & 19.8 \\
\hline 4 & 30 & 463.8 & 2.1 & 465 & 4.1 & 8.8 \\
\hline
\end{tabular}

*Apparent density is obtained by weight divided by apparent volume.

Apparent volume is obtained by thickness multiplied by area.

Table 3. Physical and Electrical Properties of Boehmite-Alumina Coating Films

\begin{tabular}{|c|c|c|c|c|c|c|c|}
\hline No & $\begin{array}{c}\mathrm{AlOOH} \text { sol } \\
(\mathrm{wt} \%)\end{array}$ & $\begin{array}{l}\text { Aging time } \\
\text { (h) }\end{array}$ & $\begin{array}{l}\text { Weight of Coating } \\
\left(\mathrm{mg} / \mathrm{cm}^{2}\right)\end{array}$ & $\begin{array}{r}\text { Density } \\
\left(\mathrm{g} / \mathrm{cm}^{3}\right)\end{array}$ & $\begin{array}{c}\text { Thickness } \\
(\mu \mathrm{m})\end{array}$ & $\begin{array}{c}\text { Breakdown } \\
\text { voltage }\left(\mathrm{kV}_{\mathrm{DC}}\right)\end{array}$ & $\begin{array}{c}\text { Breakdown } \\
\text { strength }(\mathrm{kV} / \mathrm{mm})\end{array}$ \\
\hline 1 & \multirow{6}{*}{10} & 0.5 & 8.9 & 2.1 & 42.8 & 4.04 & 94.4 \\
\hline 2 & & 1 & 10.8 & 2.0 & 52.6 & 4.97 & 94.4 \\
\hline 3 & & 18 & 10.4 & 2.9 & 36.4 & 3.18 & 87.4 \\
\hline 4 & & 24 & 6.5 & 2.3 & 27.6 & 2.21 & 80.1 \\
\hline 5 & & 51 & 3.8 & 1.8 & 20.6 & 1.19 & 57.8 \\
\hline 6 & & 72 & 2.7 & 1.7 & 16.2 & 1.11 & 68.5 \\
\hline 7 & \multirow{6}{*}{15} & 0.5 & 21.9 & 3.2 & 68.2 & 5.19 & 76.1 \\
\hline 8 & & 1 & 24.3 & 2.8 & 86.8 & 7.97 & 91.8 \\
\hline 9 & & 18 & 17.4 & 3.9 & 44.2 & 3.28 & 74.2 \\
\hline 10 & & 24 & 9.3 & 4.0 & 23.2 & 3.43 & 147.8 \\
\hline 11 & & 51 & 4.3 & 3.0 & 14.4 & 1.69 & 117.4 \\
\hline 12 & & 72 & 2.7 & 2.2 & 12.4 & 1.40 & 112.9 \\
\hline 13 & \multirow{6}{*}{20} & 0.5 & 18.5 & 1.9 & 99.2 & 5.44 & 54.8 \\
\hline 14 & & 1 & 30.5 & 3.0 & 101.6 & 7.44 & 73.2 \\
\hline 15 & & 18 & 11.5 & 2.3 & 49.4 & 4.97 & 100.6 \\
\hline 16 & & 24 & 9.8 & 2.1 & 46.0 & 5.02 & 109.1 \\
\hline 17 & & 51 & 4.2 & 1.0 & 40.4 & 1.95 & 48.2 \\
\hline 18 & & 72 & 3.7 & 0.6 & 38.2 & 1.37 & 35.8 \\
\hline
\end{tabular}

particles although thicknesses of electric insulation coating films were increased, resulting in a decrease in breakdown voltages and dielectric breakdown strengths. Thus, the presented value of dielectric breakdown strength was greater than those for the composite of micron-sized $\mathrm{SiO}_{2}$ added to epoxy base $(23.9 \sim 27.3 \mathrm{kV} / \mathrm{mm}),{ }^{14)}$ the alumina-silica composite $(11 \mathrm{kV} / \mathrm{mm}),{ }^{12)}$ alumina-boehmite $(50 \mathrm{kV} / \mathrm{mm}),{ }^{14)}$ general porcelain $(25 \mathrm{kV} / \mathrm{mm})$ exhibiting an excellent material property.

Based on the study results where the highest breakdown voltage was observed when the applied voltage was $10 \mathrm{~V}$, experiments were conducted with the applied voltage set at $10 \mathrm{~V}$ upon implementation of additional experiments. That is to say, the applied voltage is considered to be an important factor affecting structural filling factor between the solgel binder and the filler.

\subsection{Preparation of EPD organic-inorganic coating films as a function of concentrations and change in aging times of boehmite suspension}

Upon preparation of organic-inorganic coating films using sol-gel process, the sol-gel binder is one of the important elements determining structural properties of electric insulation films. Material properties of electric insulation films as a function of concentrations and change in aging times of boehmite suspension are shown in Table 3. Fig. 9 shows a graph indicating thicknesses and breakdown voltages of organic-inorganic electric insulation coating films as a function of boehmite concentrations and change in aging times of the sol-gel binder. Although thicknesses of coating films were increased irrespective of boehmite concentrations in the section where the aging times of the sol-gel binder was increased from 30 minutes to $1 \mathrm{~h}$, thicknesses of the organic-inorganic electric insulation coating films were 


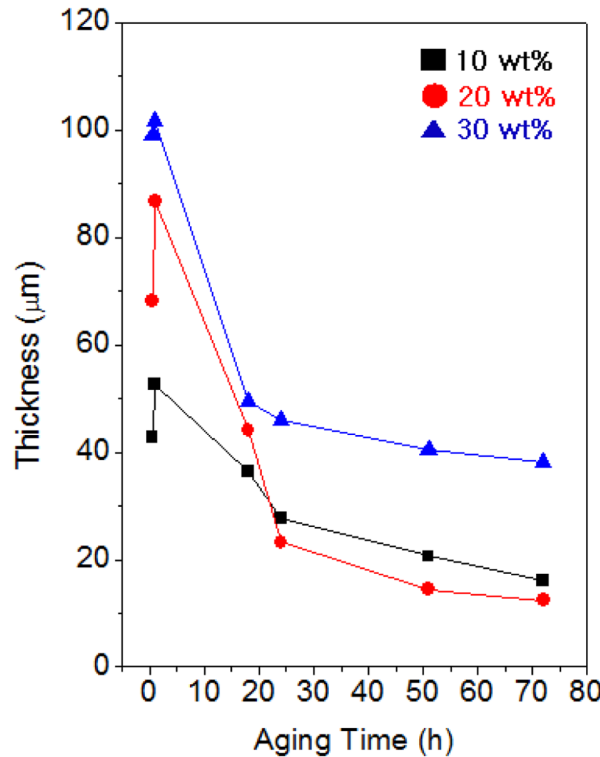

(a)

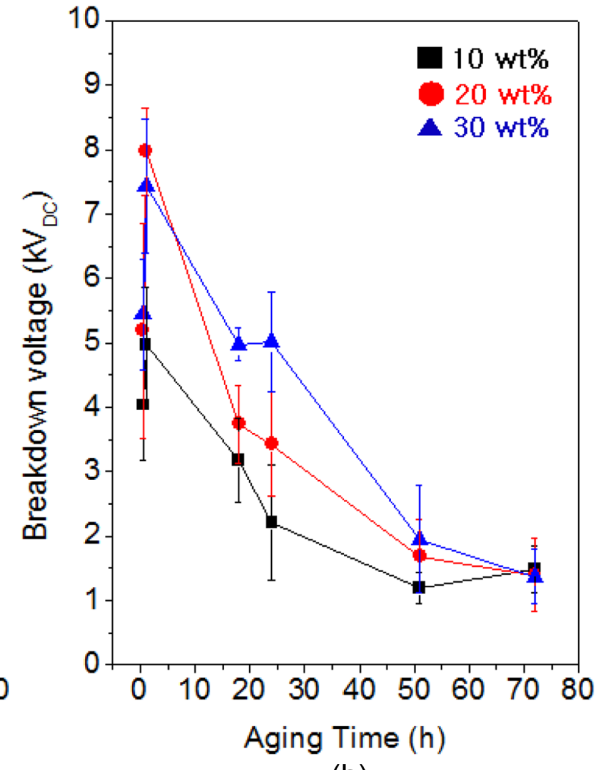

(b)

Fig. 9. (a) Thickness and (b) breakdown voltage in terms of aging time in various contents of boehmite in coating films.

rather decreased in the section where the aging times were increased from $1 \mathrm{~h}$ to $72 \mathrm{~h}$ (Fig. 9(a)).

The sol-gel binder with an increased aging time becomes to have a polymer network structure with a polymeric structure, larger than particles of the plate-shaped alumina, and the sol-gel binder is presumably coated on the substrate of cathode upon EPD coating after the plate-shaped alumina with large surface charges. Also, gradual reduction of thicknesses as a function of aging times suggests production of electric insulation films with a reduced thickness by decreasing the intensities of electric field as the coating agent with a huge network structure is coated according to lamination.

Figure 9(b) is a graph of analyzing breakdown voltages to consider electrical characteristics of the organic-inorganic coating films as a function of change in aging times for the sol-gel binder. Breakdown voltages are affected by thicknesses of coating films, being generally the higher, the larger the thicknesses. When an aging time of the sol-gel binder was $1 \mathrm{~h}$ and the concentration of boehmite suspension $15 \mathrm{wt} \%$, the highest breakdown voltage was observed. Although the thickness of the coating film was smaller than that for $20 \mathrm{wt} \%$, the high breakdown voltage of $8 \mathrm{kV}$ is considered to have appeared at the thickness of about $87 \mu \mathrm{m}$ by forming a dense film as the sol-gel binder was filling air gaps between the plate-shaped alumina particles. When aging times became longer than $1 \mathrm{~h}$, dielectric breakdown voltages were decreased, which presumably occurred as the thicknesses of coating films were decreased. For the aging time of $1 \mathrm{~h}$, no large difference in breakdown voltages appeared to occur as a function of the boehmite contents.

More detailed descriptions may be given through fracture surface images (Fig. 10) of the coating films as a function of change in aging times for the sol-gel binder (15 wt\%,

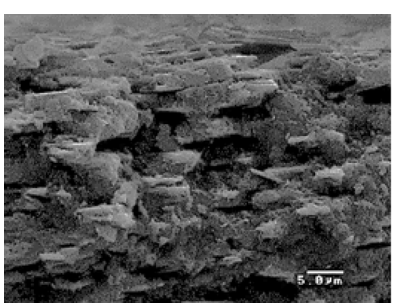

(a)

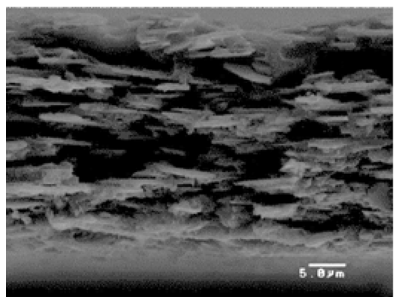

(c)

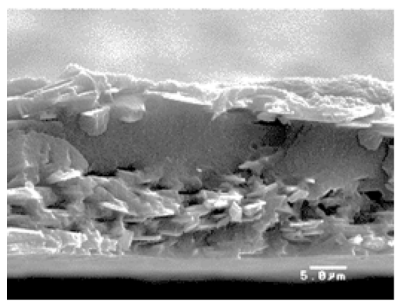

(e)

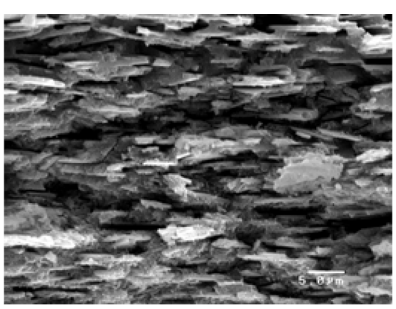

(b)

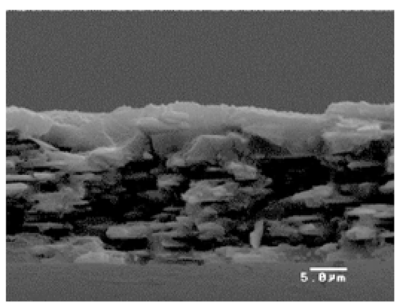

(d)

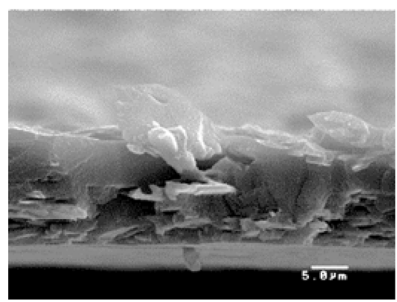

(f)
Fig. 10. Cross-sectional SEM images of the coatings in $15 \mathrm{wt} \%$ AlOOH coatings by EPD as a function of aging time of (a) $0.5 \mathrm{~h}$, (b) $1 \mathrm{~h}$, (c) $18 \mathrm{~h}$, (d) $24 \mathrm{~h}$, (e) $51 \mathrm{~h}$, (f) $72 \mathrm{~h}$.

$10 \mathrm{~V}, 10 \mathrm{~min})$. In the case of electric insulation coating film (Fig. 10 (a)) prepared by using a slurry having undergone 30 minutes of aging, the sol-gel binder could be affirmed to fill empty spaces between alumina particles 


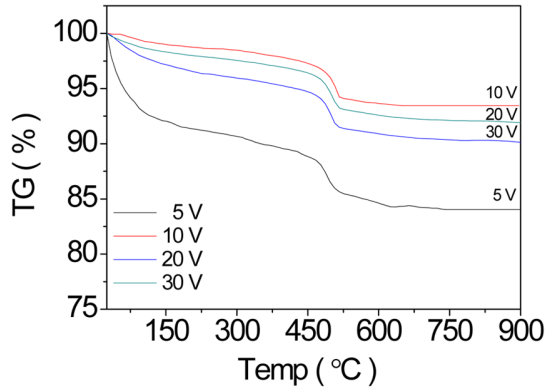

(a)

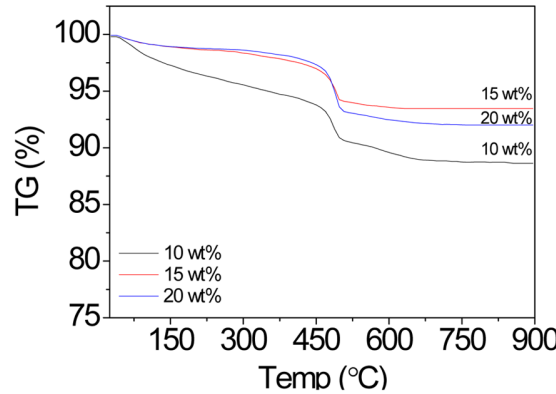

(b)

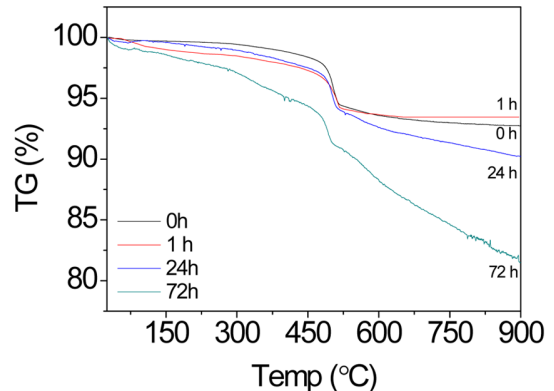

(c)

Fig. 11. Thermogravimetric analysis according to (a) applied voltage, (b) contents of boehmite for aging time of $1 \mathrm{~h}$, (c) $15 \mathrm{wt} \%$ $\mathrm{AlOOH}$ coating films as a function of aging time.

although not many alumina particles existed. In the case of coating film (Fig. 10(b)) with $1 \mathrm{~h}$ of aging time for the sol-gel binder, the plate-shaped alumina particles are observed to be densely configured by the sol-gel binder while being oriented.

As the aging time was increased to $24 \sim 72 \mathrm{~h}$, alumina particles within the coating film appeared to be reduced while only the sol-gel binder was coated(Fig. 10(d) (f)). With an increase in aging times, networks were formed through sol-gel reaction so as to increase viscosities of the slurry and hinder movement of the plate-shaped particles, and hence only a part of the sol-gel binder appears to have been coated. Namely, the fact that a large thickness and a high dielectric breakdown voltage was observed under the condition of aging time being $1 \mathrm{~h}$ is expected to be attributable to the fact that the network formed a relatively dense structure accompanied by a few defects within the coating film through aging of the sol-gel binder for $1 \mathrm{~h}$ by filling the air gaps between alumina particles without hindering movement of alumina particles.

\subsection{Thermal stability of electric insulation coating films}

Figure 11 shows a graph of analyzing through TGA the thermal characteristics of electric insulation films prepared as a function of boehmite contents, aging times for the solgel binder, and a change in applied voltages. Fig. 11(a) is a TGA graph for electric insulation coating films as a function of change in applied voltages in the range of $5 \sim 30 \mathrm{~V}$, showing experimental data where the boehmite suspension concentration, aging time for sol-gel binder and EPD lamination time were fixed at $15 \mathrm{wt} \%, 1 \mathrm{~h}$ and 10 minutes, respectively. In Fig. 11, drastic decomposition of the sol-gel binder staring at $500^{\circ} \mathrm{C}$ was observed.

When the applied voltages were increased to $5,10,20,30 \mathrm{~V}$, the corresponding weight reductions of coating films according to TGA were observed to be $16 \%, 7 \%, 10 \%, 7.5 \%$, respectively. At the low applied voltage of $5 \mathrm{~V}$, the contents of solgel binder were higher than the coating ratios of the plateshaped alumina so that the weight reductions are considered to have appeared great. Meanwhile, when the applied voltage was higher than $10 \mathrm{~V}$, the coating rates became higher so that the weight reductions are expected to be gradually decreased while the coating ratios of the plateshaped alumina coated per unit time were increased. Also, the film coated at $10 \mathrm{~V}$ showed a smaller weight reduction than the film coated at $20 \mathrm{~V}$, suggesting that the coating film had a dense structure so as to undergo less pyrolysis than the remaining coating films.

Figure 11(b) shows a TGA result of electric insulation coating films as a function of change in contents of the boehmite sol-gel binder. With an increase in boehmite contents, weight changes by $12.5 \%, 7 \%, 7.5 \%$ were indicated, respectively. Among the pyrolyzed electric insulation films, pyrolysis of the electric insulation films formed with $15 \mathrm{wt} \%$ of boehmite was the least, which suggests that the boehmitecontaining alumina and the boehmite formed a dense structure. Since alumina surrounding boehmite had a high heat resistance, it is considered to suppress pyrolysis of the boehmite.

In Fig. 11(c), thermal analysis was conducted for the electric insulation films prepared with $15 \mathrm{wt} \%$ boehmite sol-gel binder as a function of aging times. As the aging times were increased, the weight reductions by $7.5,7,10,12 \%$ were observed. The weight reduction of $7 \%$ shown by an electric insulation film was presumably caused by the fact that smooth heat transfer into specimens according to the rates of temperature rise was not realized since the well oriented plate-shaped alumina blocked high-temperature heat transfer, realizing a dense structure with the boehmite sol-gel binder aging treated for $1 \mathrm{~h}$. Namely, when the aging times were long, the heat transfer rate was considered to be continuously determined by fine porous structures without densification of the electric insulation films being realized.

\section{Conclusions}

With boehmite sol and methyltrimethoxysilane as starting materials, a binder was prepared by sol-gel method, and coating slurry was prepared by adding $10 \mathrm{wt} \%$ of plateshaped alumina. The binder was prepared by aging for $0.5 \sim$ $72 \mathrm{~h}$ with boehmite contents being $10 \sim 20 \mathrm{wt} \%$. For prepa- 
ration of hybrid coating films, electrophoretic deposition was conducted, with applied voltages being varied in the range of $5 \sim 30 \mathrm{~V}$. When the binder was aged for $1 \mathrm{~h}$ with an applied voltage of $10 \mathrm{~V}$ imposed, the hybrid coating films showed the results showing a high electric insulation. Upon observation of cross-sections of the films, it is considered attributable to the fact that the films as a whole had a dense structure since the gaps between laminated plate-shaped alumina were filled sufficiently by the sol-gel binder. On the other hand, the coating film with aging treatment for $72 \mathrm{~h}$ was observed to have low electric insulation properties as the network structure of binder had a polymeric structure upon preparation so that the films with relatively low alumina contents were formed and denseness of the binder was reduced. When the aging time was $1 \mathrm{~h}$, the weight reduction resulting from pyrolysis was $7 \%$ which was smaller than the weight reduction (12\%) for $72 \mathrm{~h}$ of aging. When the applied voltages were increased upon electrophoretic coating of alumina slurry containing the sol-gel binder, internal pores were observed at fracture surfaces showing the results of degradation in denseness of alumina lamination films as well as electric insulation characteristics while the coating thicknesses per unit time and the alumina contents within the films were increased.

\section{Acknowledgments}

This article was supported by the Convergence Pioneer Project (NRF-2010-0019468) of Ministry of Science, ICT and Future Planning, for which the authors are grateful.

\section{REFERENCES}

1. M. Guglielmi, "Sol-gel Coaitngs on Metals," J. Sol-Gel Sci. Technol., 8 [1] 443-49 (1997).

2. J. Li, Y. Zhao, J. Hu, L. Shu, X. Shi, "Anit-icing Performance of a Superhydrophobic PDMS/Modified Nano-silica Hybrid Coating for Insulators," J. Adhes. Sci. Technol., 26 [4] 665-79 (2012).

3. C. Bondoux, P. Prene, P. Belleville, F. Guillet, S. Lambert, B. Minot, and R. jerisian, "MgO Insulating Films Prepared by Sol-gel Route for SiC Substrate," J. Eur. Ceram. Soc., 25 [12] 2795-98 (2005).

4. S. H. Messaddeq, S. H. Pulcinelli, C. V. Santilli, A. C. Guastaldi, and Y. Messaddeq, "Microstructure and Corrosion Resistance of Inorganic-organic ( $\mathrm{ZrO}_{2}$-PMMA) Hybrid Coatings on Stainless Steel," J. Non-Cryst. Solids, 247 [1] 164-70 (1999).

5. J. Batey, T. Tierney, J. Stasiak, and T. N. Nguyen, "Plasam-enhanced CVD of High Quality Insulating Films," Appl. Surf. Sci., 39 [1] 1-15 (1989).

6. P. Vuoristo, T. Mäntylä, and P. Kettunen, "Properties of Magnetron-sputtered Electrically Insulating $\mathrm{Al}_{2} \mathrm{O}_{3}$ Coatings on Copper," J. Mater. Sci, 27 [18] 4985-96 (1992).

7. E. Celik, I. H. Mutlu, H. Okuyucu, and Y. S. Hascicek, "Electrical Characterization of Ceramic Insulation Coatings for Magnet Technology," IEEE Trans. Appl. Supercond., 11 [1] 2881-84 (2001).

8. L. Besra and M. Liu, "A Review on Fundamentals and Applications of Electrophoretic Deposition," Prog. Mater. Sci., 52 [1] 1-61 (2007).

9. J. J. Park, "Electrical Insulation Breakdown Strength in Epoxy/Spherical Alumina Composites for HV Insulation," Trans. Electr. Electron. Mater., 14 [2] 105-9 (2013).

10. O. Cakiroglu, L. Arda, and Y. S. Hascicek, "High Voltage Breakdown Studies of Sol-gel $\mathrm{MgO}^{-} \mathrm{ZrO}_{2}$ Insulation Coatings under Various Pressures at $298 \mathrm{~K}$ and $77 \mathrm{~K}$," Phys. C, 422 [3] 117-26 (2005).

11. T. Olding, M. Sayer, and D. Barrow, "Ceramic Sol-gel Composite Coatings for Electrical Insulation," Thin Solid Films, 398 581-86 (2001).

12. H. Ji, D. H. Kim, H. J. Park, S. H. Lee, D. S. Kim, Y. H. Kim, and H. M. Kim, "Preparation of Alumina-Silica Composite Coatings by Electrophoretic Deposition and their Electric Insulation Properties (in Korean)," J. Korean Ceram. Soc., 51 [3] 177-83 (2014).

13. H. J. Park, D. H. Kim, Y. H. Kim, and H. M. Lim, "Electrophoretic Deposition of Sol-gel Coating Comprising Alumina and Boehmite for Organic-inorganic Hybrid Film," submitted.

14. J. H. Kwon, S. H. Cho, Y. M. Kim, and K. J. Lim, "Investigation on DC Breakdown Characteristic of Nano/Micro Epoxy (in Korean)," J. Kor. Inst. Electr. Eng., 2011 [7] 1599-600 (2011). 